\title{
Children and young people with perinatal HIV in Europe: epidemiological situation in 2014 and implications for the future
}

Writing group for the Kids to Adults Working Group and Data Management and Harmonisation Group in EuroCoord ${ }^{1}$

1. The members of the writing group are listed at the end of the article

Correspondence: Ali Judd (a.judd@ucl.ac.uk)

Citation style for this article:

Writing group for the Kids to Adults Working Group and Data Management and Harmonisation Group in EuroCoord. Children and young people with perinatal HIV in Europe: epidemiological situation in 2014 and implications for the future. Euro Surveill. 2016;21(10):pii=30162. DOI: http://dx.doi.org/10.2807/1560-7917.

ES.2016.21.10.30162

Accurate ascertainment of the number of children living with human immunodeficiency virus (HIV) is important to plan paediatric and adolescent health services. In Europe, the first generation of perinatally HIV-infected survivors are transferring to adult care and their health needs are unknown. We undertook an online survey of HIV cohort studies participating in the EuroCoord Network of Excellence to ascertain the number of perinatally HIV-infected (pHIV) patients included, to compare it with those published by the European Centre for Disease Prevention and Control (ECDC) and the World Health Organization (WHO) and to assess the ability of countries to follow up pHIV patients after transfer to adult care. At the end of 2013, 16 countries in EuroCoord reported 8,229 pHIV patients in follow-up in cohorts, compared with 5,160 cumulative diagnoses reported by the ECDC in the same area. Follow-up of pHIV patients after transfer to adult care varied. It is likely that the number of diagnoses of perinatal HIV reported to ECDC is an underestimate, although this varies by country. Further work is needed to refine estimates and encourage follow-up in adult HIV cohorts to investigate long-term outcomes and improve the care of the next generation of children with HIV.

\section{Background}

Since 2008, the European Centre for Disease Prevention and Control (ECDC) and the World Health Organization Regional Office for Europe (WHO/Europe) have jointly coordinated surveillance of human immunodeficiency virus (HIV) and acquired immunodeficiency syndrome (AIDS) in Europe, covering all 53 countries in the European region [1]. HIV is a major public health issue in Europe, with an estimated 136,000 new infections diagnosed in 2013, of which 29,000 were from the European Union and European Economic Area (EU/ EEA, comprising 30 countries) and 80,000 from the Russian Federation [1]. ECDC/WHO data suggest that the cumulative number of HIV diagnoses attributed to mother-to-child transmission (henceforth referred to as perinatally HIV-infected (pHIV) patients) in the EU/EEA region was 5,636 from when reporting began to the end of 2013 [1].

The estimated number of new infections in children globally has decreased from 450,000 in 2005 to 240,000 in 2013 , mainly due to scale-up of interventions to prevent mother-to-child transmission (MTCT), while access to antiretroviral therapy (ART) for infected children has increased $[1,2]$. As a consequence, the face of the paediatric HIV epidemic is rapidly changing, particularly in Western Europe where, although few infants are born with HIV, there are still new paediatric diagnoses in migrant children who were born elsewhere, predominantly sub-Saharan Africa [3]. Furthermore, due to widespread use of ART, an increasing proportion of the pHIV population are surviving into adulthood and now transferring to adolescent and adult HIV care.

Although in most of Western Europe, pHIV young people form a relatively small group, they are likely to have different health needs compared with young adults with sexually acquired HIV [4,5]. Small studies have suggested that as pHIV patients enter adult life they are at high risk of mortality [6], co-morbidities [7], treatment failure [8] and disengagement from care [9]. They may have additional challenges which can affect health outcomes, including neurodevelopment and mental health issues [10-12], stigma and discrimination [13], HIV disclosure issues [14] and parental loss [15]. Critically, the adolescent period coincides with broader social transformations in young people's lives which can substantially shape their transition experience as well as health outcomes $[16,17]$.

A comprehensive understanding of the epidemiology of HIV among children and young people at the 
Number of perinatal patients in HIV cohorts in countries in the EU/EEA area, to end of $2013(\mathrm{n}=8,229)$
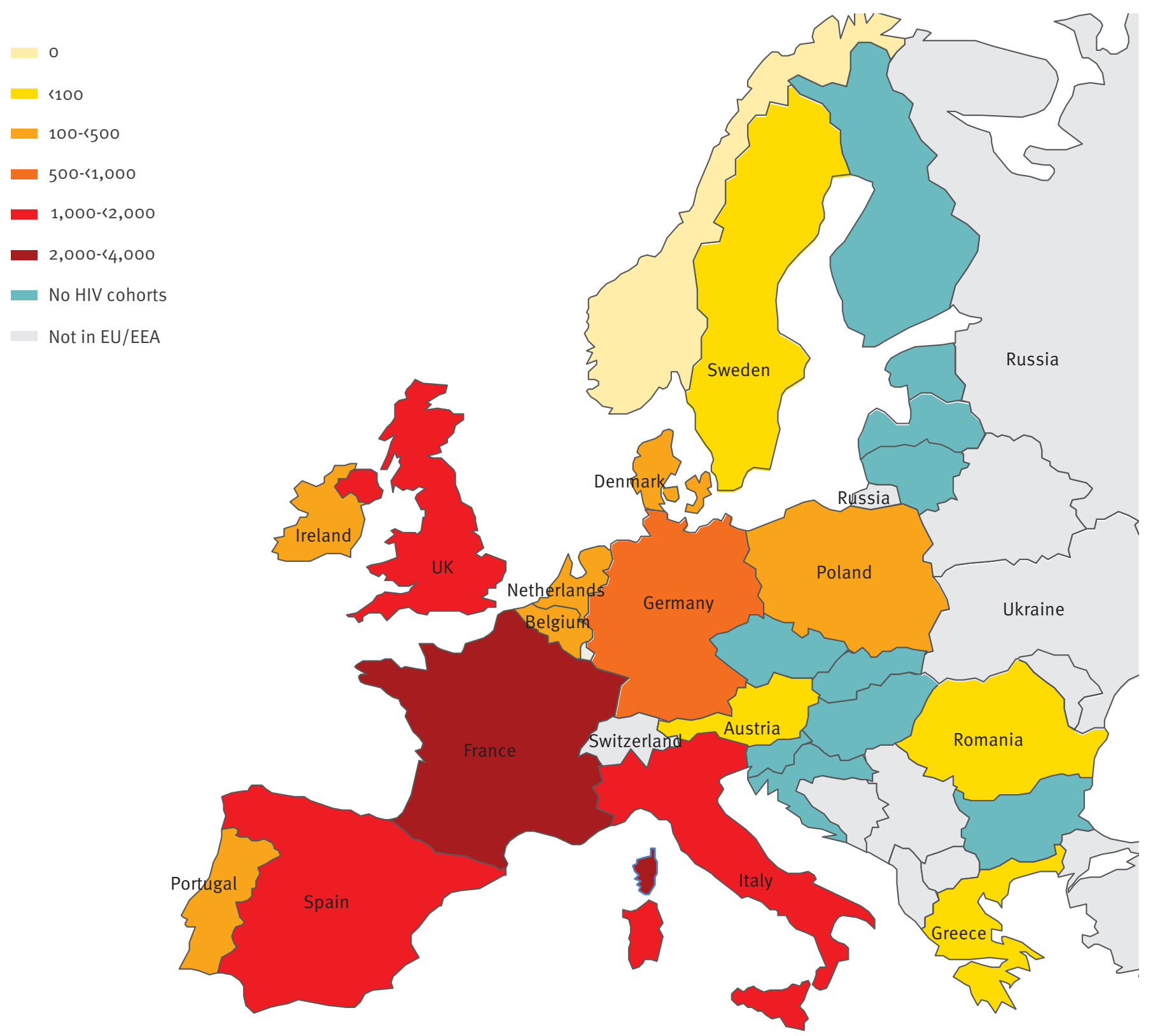

EU/EEA: European Union and European Economic Area; HIV: human immunodeficiency virus.

national and European level is important for efficient planning of health services. Cohort studies provide a unique opportunity to monitor the changing epidemiology of HIV in this group longitudinally and to follow pHIV young people during transition to adulthood and beyond. Therefore, we undertook a survey of HIV cohort studies participating in the EuroCoord Network of Excellence [18] to ascertain the number of pHIV patients included and their geographical distribution. We compared these estimates with those published by $\mathrm{ECDC} / \mathrm{WHO}$ which are largely derived from surveillance of new HIV diagnoses reported by countries in Europe. In addition, we explored the extent to which European cohorts were able to continue follow-up of this group as they transition from paediatric to adult care.

\section{Methods}

The EuroCoord Network (www.eurocoord.net) consists of four founding networks: Concerted Action on SeroConversion to AIDS and Death in Europe (CASCADE), a network of adult seroconverter cohorts, Collaboration of Observational HIV Epidemiological Research in Europe (COHERE), a collaboration of paediatric and adult cohorts, EuroSIDA, a large cohort of adult European patients, and Paediatric European Network for the Treatment of AIDS - European Pregnancy and Paediatric HIV Cohort Collaboration (PENTA-EPPICC), 
a multinational network of centres participating in clinical trials and observational studies of HIV-infected pregnant women and children.

Within EuroCoord, a cross-network working group (the 'Kids to Adults Working Group') was established to investigate the number of pHIV patients included in adult and paediatric cohorts in each Network, and the degree to which paediatric and adult cohorts were linked and able to follow up young people after transition to adult care. This Group collaborated with the EuroCoord Data Management and Harmonisation Group to obtain data from the 2013 EuroCoord Data Inventory survey (a sample questionnaire can be found here: https://chip-crf.info/wp4/survey.php) which collects metadata from cohorts within EuroCoord on an annual basis, including the number of patients ever reported to each cohort who were perinatally infected. It was not possible to also request data on the number alive and/or in care as most cohorts did not have national coverage, and therefore would not be able to differentiate a patient moving to a different clinic from a patient emigrating or dying, and many cohorts were not able to follow patients after transition to adult care and therefore did not have data on patient outcomes in adult care. Data on age and age at transition were not collected. An additional questionnaire was sent to four cohorts which had recently joined the PENTA-EPPICC network but who were yet to complete the EuroCoord Data Inventory. Cohorts varied from single hospital sites to studies with regional or national coverage, and thus we reasoned that in most cases, they represented a subset of the true size of the pHIV population in each country. The survey and the additional questionnaires were completed by cohort principal investigators, data managers and/or statisticians.

Descriptive statistics were used, and analyses were restricted to cohorts in the EU/EEA area (i.e. excluding Russia, Switzerland and Ukraine) in order to provide comparability to published ECDC estimates of the cumulative number of HIV diagnoses in persons infected through mother-to-child transmission since the start of reporting (which varied by country) and to the end of 2013 [1]. All analyses were undertaken using STATA 13.

\section{Results}

At the time of the survey in 2013, EuroCoord included 45 cohorts across 16 countries in the EU/EEA area in Europe; The Figure shows the 26 EU/EEA countries and the number of pHIV patients enrolled. Within the EU/ EEA area, 10 countries did not have any HIV cohorts in EuroCoord (Bulgaria, Croatia, Czech Republic, Estonia, Finland, Hungary, Latvia, Lithuania, Slovakia and Slovenia) and additionally, the Norwegian cohort in EuroCoord reported having no data on pHIV patients. The other 15 countries reported having pHIV patients represented in cohort studies (Figure).
Cohorts in France, Italy, Spain and the United Kingdom (UK) reported the largest number of pHIV patients ever in follow-up, with over 1,000 patients per country by the end of 2013. The German cohort reported between 500 and 999 patients, and Belgium, Denmark, Ireland, the Netherlands, Poland and Portugal reported between 100 and 499 patients. Austria, Greece, Romania and Sweden each reported fewer than 100 patients. Together, all 16 countries (including Norway) reported a total of 8,229 pHIV patients ever followed up in HIV cohorts in the EU/EEA area. Spain had three paediatric cohorts, and any double counting of patients had been removed before data submission to the EuroCoord Data Inventory. However, overlap between adult and paediatric cohorts could have occurred in France, Germany, Italy, Spain and the UK, but not in Belgium. This effect was potentially largest in France, whose adult cohorts reported 1,608 pHIV patients, some of whom could have been included in more than one adult cohort or in the 698 patients reported by the paediatric cohort. When restricted to paediatric-only cohorts, a total of 5,595 pHIV patients were reported.

The number of pHIV patients in each EU/EEA country included in EuroCoord is compared with the number reported to ECDC/WHO in the Table. There were 16 EuroCoord countries with HIV cohorts reporting pHIV patients compared with 30 EU/EEA countries with ECDC estimates of perinatal HIV diagnoses. The 8,229 patients with perinatal HIV infection in cohorts in EuroCoord in these 16 countries compare to 5,160 cumulative diagnoses reported to ECDC in the same countries. Countries varied in the degree to which HIV cohort estimates were similar to ECDC estimates. For Austria, Denmark, the Netherlands and the UK, cohort estimates were within $a+/-25 \%$ window of ECDC estimates. For Germany, Greece, Norway, Portugal, Romania and Sweden, cohort numbers were less than half the ECDC estimates. However, in France, Italy and Spain (three of the four largest MTCT patient cohorts) the reverse was true, with cohort estimates being more than five times higher than ECDC estimates, assuming no double counting of patients in cohorts.

Within the EuroCoord cohorts, the extent to which paediatric and adult cohorts were linked for follow-up of pHIV patients varied widely across the 15 countries with pHIV cohorts (i.e. excluding Norway). In Denmark, Greece, Netherlands and Romania, paediatric and adult data were already held in the same database; however these countries accounted for only 397 (5\%) of the 8,229 patients. In the UK and Ireland, mechanisms for linkage of paediatric and adult data were in progress, through a multifaceted approach including extension of the national paediatric cohort ('CHIPS') [3] to monitor patients in adult care ('CHIPS+') [19], enrolment of a subsample of the paediatric cohort into the Adolescents and Adults Living with Perinatal HIV (AALPHI) cohort, which also includes a group of HIVnegative sibling controls [20], and linkage to national surveillance data and the UK Collaborative HIV Cohort 
TABLE

Patients who acquired HIV through mother-to-child transmission included in EuroCoord cohorts $(\mathrm{n}=5,595)$ and reported to ECDC surveillance to the end of $2013(n=5,636)$

\begin{tabular}{|c|c|c|c|c|c|c|c|c|}
\hline \multirow{2}{*}{$\begin{array}{l}\text { Data source } \\
\text { EU/EEA } \\
\text { country }\end{array}$} & \multicolumn{6}{|c|}{ EuroCoord cohorts } & \multirow{2}{*}{$\begin{array}{l}\text { ECDC } \\
\text { Number } \\
\text { of MTCT } \\
\text { patients }\end{array}$} & \multirow[b]{2}{*}{$\begin{array}{c}\text { Proportion of } \\
\text { patients in } \\
\text { EuroCoord/ECDC }\end{array}$} \\
\hline & $\begin{array}{c}\text { Number of } \\
\text { adult cohorts } \\
\text { reporting MTCT } \\
\text { patients }^{\mathrm{a}}\end{array}$ & $\begin{array}{c}\text { Number of } \\
\text { paediatric- } \\
\text { only } \\
\text { cohorts }\end{array}$ & $\begin{array}{l}\text { Coverage of } \\
\text { paediatric } \\
\text { cohort }\end{array}$ & $\begin{array}{l}\text { Number } \\
\text { of MTCT } \\
\text { patients in } \\
\text { adult cohorts }\end{array}$ & $\begin{array}{c}\text { Number of } \\
\text { MTCT patients } \\
\text { in paediatric } \\
\text { cohorts }\end{array}$ & $\begin{array}{l}\text { Total number } \\
\text { of MTCT } \\
\text { patients }\end{array}$ & & \\
\hline Austria & 1 & 0 & NA & 53 & 0 & 53 & 54 & $98 \%$ \\
\hline Belgium & 1 & 1 & $\begin{array}{c}\text { Single } \\
\text { hospital }\end{array}$ & 65 & 163 & 228 & 428 & $53 \%$ \\
\hline Bulgaria & 0 & 0 & NA & 0 & 0 & 0 & 19 & NA \\
\hline Croatia & 0 & 0 & NA & 0 & 0 & 0 & 13 & NA \\
\hline Cyprus & 0 & 0 & NA & 0 & 0 & 0 & 3 & NA \\
\hline $\begin{array}{l}\text { Czech } \\
\text { Republic }\end{array}$ & 0 & 0 & NA & 0 & 0 & 0 & 6 & NA \\
\hline Denmark & 0 & 1 & $\begin{array}{c}\text { Single } \\
\text { hospital }\end{array}$ & 0 & 100 & 100 & 96 & $104 \%$ \\
\hline Estonia & 0 & 0 & NA & 0 & 0 & 0 & 46 & NA \\
\hline Finland & 0 & 0 & NA & 0 & 0 & 0 & 24 & NA \\
\hline France & 3 & 1 & Multiregional & 1,608 & 698 & 2,306 & 388 & $594 \%$ \\
\hline Germany & 2 & 1 & Multiregional & 21 & 4 & 25 & 326 & $8 \%$ \\
\hline Greece & 1 & 0 & NA & 0 & 9 & 9 & 64 & $14 \%$ \\
\hline Hungary & 0 & 0 & NA & 0 & 0 & 0 & 11 & NA \\
\hline Iceland & 0 & 0 & NA & 0 & 0 & 0 & 1 & NA \\
\hline Ireland & 0 & 1 & National & 0 & 95 & 95 & 75 & $127 \%$ \\
\hline Italy & 2 & 1 & Multiregional & 22 & 1,557 & 1,579 & 136 & $1,161 \%$ \\
\hline Latvia & 0 & 0 & NA & 0 & 0 & 0 & 59 & NA \\
\hline Lithuania & 0 & 0 & NA & 0 & 0 & 0 & 3 & NA \\
\hline Luxembourg & 0 & 0 & NA & 0 & 0 & 0 & 7 & $\mathrm{NA}$ \\
\hline Malta & 0 & 0 & NA & 0 & 0 & 0 & 0 & NA \\
\hline $\begin{array}{l}\text { The } \\
\text { Netherlands }\end{array}$ & 1 & 0 & National & 261 & 0 & 261 & 277 & $94 \%$ \\
\hline Norway & 0 & 0 & NA & 0 & 0 & 0 & 76 & $0 \%$ \\
\hline Poland & 0 & 1 & $\begin{array}{c}\text { Single } \\
\text { hospital }\end{array}$ & 0 & 111 & 111 & 193 & $58 \%$ \\
\hline Portugal & 0 & 1 & $\begin{array}{c}\text { Single } \\
\text { hospital }\end{array}$ & 0 & 40 & 40 & 393 & $10 \%$ \\
\hline Romania & 0 & 1 & $\begin{array}{c}\text { Single } \\
\text { hospital }\end{array}$ & 0 & 27 & 27 & 243 & $11 \%$ \\
\hline Slovakia & 0 & 0 & NA & 0 & 0 & 0 & 0 & NA \\
\hline Slovenia & 0 & 0 & $\mathrm{NA}$ & 0 & 0 & 0 & 7 & $\mathrm{NA}$ \\
\hline Spain & 2 & 3 & National & 278 & 1,184 & 1,462 & 86 & $1,700 \%$ \\
\hline Sweden & & 1 & $\begin{array}{c}\text { Single } \\
\text { hospital }\end{array}$ & 0 & 75 & 75 & 203 & $37 \%$ \\
\hline $\begin{array}{l}\text { United } \\
\text { Kingdom }\end{array}$ & 1 & 1 & National & 131 & 1,727 & 1,858 & 2,399 & $77 \%$ \\
\hline $\begin{array}{l}\text { Total for } \\
\text { countries } \\
\text { with } \\
\text { EuroCoord } \\
\text { data } \\
\text { available }\end{array}$ & 14 & 14 & NA & 2,439 & 5,790 & 8,229 & 5,160 & $159 \%$ \\
\hline $\begin{array}{l}\text { Total all } \\
\text { countries }\end{array}$ & 14 & 14 & NA & 2,439 & 5,790 & 8,229 & 5,636 & NA \\
\hline
\end{tabular}

ECDC: European Centre for Disease Prevention and Control; EU/EEA: European Union and European Economic Area; HIV: human immunodeficiency virus; NA: not applicable.

${ }^{\text {a }}$ Adult cohorts may include paediatric patients while paediatric cohorts include children up to age 16 or 18 years or remaining in paediatric care. 
Study (CHIC) adult HIV cohort to enable data sharing and tracking of patients lost to follow up [21]. Belgium, Poland, Portugal and Sweden reported that paediatric and adult data linkage was possible although not yet in place. Austria and Spain reported that datasets could not be linked. For France, Germany and Italy, the cohort respondent did not know if linkage was possible.

\section{Discussion}

Results from this survey of adult and paediatric HIV cohorts in Europe indicated that, across 16 countries in the EU/EEA area, the estimated number of pHIV patients in cohorts was at least 5,595, and potentially more than 8,000 . The largest numbers were in cohorts in France, Italy, Spain and the UK, which together accounted for ca $88 \%(7,205)$ of the 8,229 patients. These four countries all have dedicated multisite paediatric cohort studies, with good geographical coverage, with the proportion of perinatal HIV diagnoses included in the Spanish [22] and UK [3] national cohorts approaching $100 \%$. However, the comparability of these countries' estimates to ECDC/WHO data varied considerably. EuroCoord cohort numbers for France, Italy and Spain were at least five times higher than ECDC/WHO new HIV diagnoses. For Italy, cohort data are not linked to the Centro Operativo AIDS national reporting system ( $\mathrm{L}$ Galli, personal communication, December 2014), and it is likely that the French and Spanish cohorts similarly operate without always reporting to ECDC/WHO and warrant further investigation. Part of the reason for the discrepancy may be that in France, Italy and Spain, HIV surveillance and reporting to ECDC only started in 2003 or later, and cases diagnosed before that time and included in these longstanding cohorts were therefore not reported. Furthermore, Italy and Spain only achieved national coverage in terms of reporting to ECDC/WHO in 2012 and 2013, respectively, and not all regions participated in earlier years of surveillance [1].

In contrast, in the UK, where data from the national paediatric cohort are sent to ECDC, there was more comparability, although the number reported by the EuroCoord cohorts was lower than that reported to ECDC. This is likely to be because the paediatric cohort estimates include all HIV diagnoses among children younger than 16 years while the national surveillance also includes new perinatal HIV diagnoses in adults (e.g. perinatally infected adults born and diagnosed abroad and entering an adult cohort without prior paediatric care in the UK). As this latter group increases with improved paediatric access to ART in Africa, estimates will deviate further in the future. For other countries, perinatal HIV infections that were diagnosed abroad may not be reported in the European country of arrival as 'new diagnoses', but may be eligible to join a cohort, potentially contributing to higher numbers in cohorts compared with ECDC data. Conversely, children who die after being reported as new diagnoses may never be eligible to join a cohort and thus contribute to higher numbers for ECDC compared with cohort data.
Although Austria, Denmark and the Netherlands had few pHIV patients overall, the EuroCoord estimates were very similar to ECDC estimates; in particular for Austria and the Netherlands, cohort data are used for surveillance and reported to ECDC ( $R$ Zangerele, personal communication, December 2014; C Smit, personal communication, June 2015). The lack of HIV cohorts in EuroCoord from many of the Baltic and Balkan states highlights the importance of reliable reporting of new cases to $\mathrm{ECDC} / \mathrm{WHO}$ in these regions, as many countries in these areas are experiencing large and rapidly growing HIV epidemics $[19,23]$. In Romania, only a single hospital cohort participates in EuroCoord, but ECDC/WHO data originate from nine regional HIV/ AIDS centres who all report to the centralised National Institute for Infectious Diseases (M Mardarescu, personal communication, June 2015).

Data on pHIV patients from six of the 14 countries with paediatric cohorts within EuroCoord were from single hospitals. Some of these countries were large, including Poland, Portugal and Romania, and these single hospitals will underestimate numbers of pHIV patients in the country. Similarly, France, Germany and Italy reported the number of pHIV patients from multiregional centres, for which coverage of the entire country is not known, again suggesting that we are underestimating the size of the pHIV population in these countries. Certainly countries with national cohorts as well as links to national surveillance should provide a more representative picture.

Cohorts from only four countries (Denmark, Greece, the Netherlands and Romania) with small numbers of pHIV patients reported that paediatric and adult data are held together, thus enabling continued uninterrupted data collection after transfer to adult care. Many children in paediatric care in Europe today will soon transfer to adult clinics which are already part of existing HIV cohort studies, so the lack of linkage constitutes a missed opportunity to monitor long-term outcomes in this group. Investment in linkages is crucial to inform future clinical care practice and policies for pHIV populations in high- and middle-income settings in Europe and elsewhere.

Globally more than 200,000 HIV-infected children are born each year despite success in scaling up initiatives for the prevention of MTCT, and more than $90 \%$ live in sub-Saharan Africa [2]. Improvements in early diagnosis, linkage to care and prompt initiation of ART mean that many will survive to adulthood. African children have had access to ART for a considerably shorter time than children from well-resourced settings, and outcomes for young people with perinatal HIV in Europe will signal the direction of future care of HIV-infected African children, highlighting the importance of ensuring long-term follow-up of European pHIV patients. Children and young people with perinatally acquired HIV are unique in terms of their disease and treatment history. Many have been and more will be treated from 
infancy or in early life $[24,25]$, with unknown outcomes in adulthood in terms of long-term treatment options, the effect of perinatal infection on accelerated ageing or life expectancy, and the impact of life-long HIV and ART exposure on future generations of pHIV patients. Therefore, it is critical that adult care providers are aware of the importance of identifying this group as perinatally HIV-infected, maximise their retention into adult care and monitor their health needs and outcomes.

\section{Conclusion}

In summary, it is likely that the overall number of diagnoses of perinatal HIV reported to ECDC/WHO may underestimate the true number of pHIV cases under care in the EU/EEA. Countries varied in the degree to which their figures differed from those of ECDC/WHO, with few cohorts having national coverage and/or being integrated into national surveillance reporting systems. Possible reasons for higher cohort numbers in countries such as France, Italy and Spain include cohorts recruiting before the start of reporting to $\mathrm{ECDC} / \mathrm{WHO}$, poor coverage of reporting to ECDC/WHO historically and inclusion of cases previously diagnosed abroad. Potential reasons for higher numbers in ECDC/WHO data for countries such as Romania and the UK include better coverage of reporting new diagnoses and inclusion of cases who died and therefore were not eligible to join some cohorts. Importantly, for many countries without HIV cohorts, ECDC/WHO data represent the best source of data on numbers of pHIV patients.

Further work is needed to link cohorts to national reporting systems country by country, to improve epidemiological estimates of the size of the pHIV population in Europe. It is also critical to ensure that adult cohort studies are ready to identify and track young people with perinatal HIV in their care. It is important that linkage occurs between paediatric and adult datasets to ensure continuity of monitoring and the ability to investigate long-term outcomes, in order to improve the care of the next generation of children with HIV infection and HIV exposure.

\section{Acknowledgements}

EuroCoord Kids to Adults Working Group members (network), ordered by name within each network: Julia del Amo (CASCADE), Pablo Rojo Conejo (COHERE), Caroline Sabin (COHERE), Josiane Warszawski (COHERE), AnneFrancoise Gennotte (EuroSIDA), David Nadal (EuroSIDA), Diana Gibb (PENTA-EPPICC), Ali Judd (PENTA-EPPICC), Claire Thorne (PENTA-EPPICC). EuroCoord Data Management and Harmonisation Group members (network), ordered by author name within each network: Ashley Olson (CASCADE), Sara Lodi (CASCADE), Nikos Pantazis (CASCADE), Julia del Amo (COHERE), Sara Lodi (COHERE), Monique Termote (COHERE), Bruno Ledergerber (EuroSIDA), Dennis Kristensen (EuroSIDA), Rikke Salbøl Brandt (COHERE), Charlotte Duff (PENTA-EPPICC), Ali Judd (PENTA-EPPICC), Yacine Saidi (PENTA-EPPICC). EuroCoord Executive Board: Fiona Burns, University College London, UK; Geneviève Chêne (Chair), University of Bordeaux, France; Dominique Costagliola (Scientific Coordinator), Institut National de la Santé et de la Recherche Médicale, France; Carlo Giaquinto, Fondazione PENTA, Italy; Jesper Grarup, Region Hovedstaden, Denmark; Ole Kirk, Region Hovedstaden, Denmark; Laurence Meyer, Institut National de la Santé et de la Recherche Médicale, France; Heather Bailey, University College London, UK; Alain Volny Anne, European AIDS Treatment Group, France; Alex Panteleev, St. Petersburg City AIDS Centre, Russian Federation; Andrew Phillips, University College London, UK, Kholoud Porter, University College London, UK; Claire Thorne, University College London, UK. EuroCoord Council of Partners: Jean-Pierre Aboulker, Institut National de la Santé et de la Recherche Médicale, France; Jan Albert, Karolinska Institute, Sweden; Silvia Asandi, Romanian Angel Appeal Foundation, Romania; Geneviève Chêne, University of Bordeaux, France; Dominique Costagliola, INSERM, France; Antonella d'Arminio Monforte, ICoNA Foundation, Italy; Stéphane De Wit, St. Pierre University Hospital, Belgium; Peter Reiss, Stichting HIV Monitoring, Netherlands; Julia Del Amo, Instituto de Salud Carlos III, Spain; José Gatell, Fundació Privada Clínic per a la Recerca Bíomèdica, Spain; Carlo Giaquinto, Fondazione PENTA, Italy; Osamah Hamouda, Robert Koch Institut, Germany; Igor Karpov, University of Minsk, Belarus; Bruno Ledergerber, University of Zurich, Switzerland; Jens Lundgren, Region Hovedstaden, Denmark; Ruslan Malyuta (Chair), Perinatal Prevention of AIDS Initiative, Ukraine; Claus Møller, Cadpeople A/S, Denmark; Kholoud Porter, University College London, United Kingdom; Maria Prins, Academic Medical Centre, Netherlands; Aza Rakhmanova, St. Petersburg City AIDS Centre, Russian Federation; Jürgen Rockstroh, University of Bonn, Germany; Magda Rosinska, National Institute of Public Health, National Institute of Hygiene, Poland; Manjinder Sandhu, Genome Research Limited; Claire Thorne, University College London, UK; Giota Touloumi, National and Kapodistrian University of Athens, Greece; Alain Volny Anne, European AIDS Treatment Group, France. EuroCoord External Advisory Board: David Cooper, University of New South Wales, Australia; Nikos Dedes, Positive Voice, Greece; Kevin Fenton, Public Health England, USA; David Pizzuti, Gilead Sciences, USA; Marco Vitoria, World Health Organisation, Switzerland. EuroCoord Secretariat: Silvia Faggion, Fondazione PENTA, Italy; Lorraine Fradette, University College London, UK; Richard Frost, University College London, UK; Andrea Cartier, University College London, UK; Dorthe Raben, Region Hovedstaden, Denmark; Christine Schwimmer, University of Bordeaux, France; Martin Scott, UCL European Research \& Innovation Office, UK. Funding: This project has received funding from the European Union's Seventh Framework Programme for research, technological development and demonstration under EuroCoord grant agreement no. 260694. We are very grateful to Anastasia Pharris at the European Centre for Disease Prevention and Control (ECDC) for reviewing a draft of this paper.

The paper describes metadata from cohort studies. All cohort studies consented to be part of the paper and have their data presented.

\section{Conflict of interest}

None declared.

\section{Authors' contributions}

All authors participated in discussions about the design of the study, the choice of statistical analyses and interpretation of the findings, and were involved in the preparation and review of the manuscript. Additionally, Ali Judd was responsible for undertaking the analyses, and acted as guarantor for the analyses and had full access to the data. Ali Judd and Diana Gibb were responsible for the study concept and design. Ali Judd and Intira Jeannie Collins interpreted the data 
and drafted the manuscript. All authors critically reviewed the manuscript.

\section{Writing Group}

Ali Judd (PENTA-EPPICC), Intira Jeannie Collins (PENTAEPPICC), Sara Lodi (CASCADE), Ashley Olson (CASCADE), Nikos Pantazis (CASCADE), Julia del Amo (COHERE), Charlotte Duff (PENTA-EPPICC), Anne-Francoise Gennotte (EuroSIDA), Dennis Kristensen (EuroSIDA), Bruno Ledergerber (EuroSIDA), David Nadal (EuroSIDA), Pablo Rojo Conejo (COHERE), Caroline Sabin (COHERE), Yacine Saidi (PENTA-EPPICC), Rikke Salbøl Brandt (COHERE), Monique Termote (COHERE), Claire Thorne (PENTA-EPPICC), Josiane Warszawski (COHERE), Diana M Gibb (PENTA-EPPICC).

\section{References}

1. European Centre for Disease Prevention and Control (ECDC) World Health Organization Regional Office for Europe (WHO/ Europe). HIV/AIDS surveillance in Europe 2013. Stockholm: ECDC; 2014. Available from: http://ecdc.europa.eu/en/ publications/Publications/hiv-aids-surveillance-reportEurope-2013.pdf

2. Joint United Nations Programme on HIV/AIDS (UNAIDS). The Gap Report. Geneva: UNAIDS. 2014. Available from: http://www.unaids.org/sites/default/files/en/media/ unaids/contentassets/documents/unaidspublication/2014/ UNAIDS Gap report en.pdf

3. Judd A, Doerholt K, Tookey PA, Sharland M, Riordan A, Menson $\mathrm{E}$, et al. Morbidity, mortality, and response to treatment by children in the United Kingdom and Ireland with perinatally acquired HIV infection during 1996-2006: planning for teenage and adult care. Clin Infect Dis. 2007;45(7):918-24. DOI: 10.1086/521167 PMID: 17806062

4. de Mulder M, Yebra G, Navas A, de José MI, Gurbindo MD, González-Tomé MI, et al. High drug resistance prevalence among vertically HIV-infected patients transferred from pediatric care to adult units in Spain. PLoS One. 2012;7(12):e52155. DOI: 10.1371/journal.pone.0052155 PMID: 23284913

5. Dollfus C, Le Chenadec J, Faye A, Blanche S, Briand N, Rouzioux C, et al. Long-term outcomes in adolescents perinatally infected with HIV-1 and followed up since birth in the French perinatal cohort (EPF/ANRS CO10). Clin Infect Dis. 2010;51(2):214-24. DOI: 10.1086/653674 PMID: 20536367

6. HIV Young Persons Network (HYPNet), Fish R, Judd A, Jungmann E, O'Leary C, Foster C. Mortality in perinatally HIV-infected young people in England following transition to adult care: an HIV Young Persons Network (HYPNet) audit.HIV Med. 2014;15(4):239-44. DOI: 10.1111/hiv.12091 PMID: 24112550

7. Lowenthal ED, Bakeera-Kitaka S, Marukutira T, Chapman J, Goldrath K, Ferrand RA. Perinatally acquired HIV infection in adolescents from sub-Saharan Africa: a review of emerging challenges.Lancet Infect Dis. 2014;14(7):627-39. DOI: 10.1016/ S1473-3099(13)70363-3 PMID: 24406145

8. Castro H, Judd A, Gibb DM, Butler K, Lodwick RK, van Sighem $A$, et al. Risk of triple-class virological failure in children with HIV: a retrospective cohort study. Lancet. 2011;377(9777):15807. DOI: 10.1016/S0140-6736(11)60208-o PMID: 21511330

9. Rice BD, Delpech VC, Chadborn TR, Elford J. Loss to followup among adults attending human immunodeficiency virus services in England, Wales, and Northern Ireland.Sex Transm Dis. 2011;38(8):685-90.PMID: 21844719

10. Malee K, Tassiopoulos K, Smith R, Hazra R, Allison S, Brouwers $P$, et al., editors. Behavioral and emotional risks among children and adolescents with perinatal HIV exposure and HIV infection. NIMH Annual International Research Conference on the Role of Families in Preventing and Adapting to HIV/AIDS; 2008; Rhode Island.

11. Wood SM, Shah SS, Steenhoff AP, Rutstein RM. The impact of AIDS diagnoses on long-term neurocognitive and psychiatric outcomes of surviving adolescents with perinatally acquired HIV.AIDS. 2009;23(14):1859-65. DOI: 10.1097/ QAD.obo13e32832d924f PMID: 19584705

12. Smith R, Chernoff M, Williams PL, Malee KM, Sirois PA, Kammerer B, et al. Impact of HIV severity on cognitive and adaptive functioning during childhood and adolescence. Pediatr Infect Dis J. 2012;31(6):592-8. DOI: 10.1097/ INF.ob013e318253844b PMID: 22592486
13. Hogwood J, Campbell T, Butler S. I wish I could tell you but I can't: adolescents with perinatally acquired HIV and their dilemmas around self-disclosure.Clin Child Psychol Psychiatry. 2013;18(1):44-60. DOI: 10.1177/1359104511433195 PMID: 22287554

14. Greenhalgh C, Evangeli M, Frize G, Foster C, Fidler S. Intimate relationships in young adults with perinatally acquired HIV: partner considerations.AIDS Care. 2013;25(4):447-50. DOI: 10.1080/09540121.2012.712671 PMID: 22909272

15. Cervia JS. Easing the transition of HIV-infected adolescents to adult care.AIDS Patient Care STDS. 2013;27(12):692-6. DOI: 10.1089/apc.2013.0253 PMID: 24073595

16. Newman C, Persson A, Miller A, Cama E. Bridging worlds, breaking rules: Clinician perspectives on transitioning young people with perinatally acquired HIV into adult care in a low prevalence setting.AIDS Patient Care STDS. 2014;28(7):381-93. DOI: 10.1089/apc.2013.0346 PMID: 24749770

17. Fegran L, Hall EO, Uhrenfeldt L, Aagaard H, Ludvigsen MS. Adolescents' and young adults' transition experiences when transferring from paediatric to adult care: a qualitative metasynthesis.Int J Nurs Stud. 2014;51(1):123-35. DOI: 10.1016/j.ijnurstu.2013.02.001 PMID: 23490470

18. EuroCoord. Cohort Registry. [Accessed: 25 Sep 2014]. Available from: http://www.eurocoord.net/cohort_registry

19. Judd A, Collins IJ, Le Prevost M, Gibb DM, Tookey P, editors. Kids to adults: tracking perinatally infected youth as they transition to adult care - the UK experience. 21st Annual Conference of the British HIV Association (BHIVA); 2015; Brighton, UK.

20. Judd A, Nunn A, Melvin D, Foster C, Winston A, Le Prevost M, et al., editors. Neurocognitive function in perinatally HIVinfected young people and HIV-negative siblings in England. 21st Annual Conference of the British HIV Association; 2015; Brighton, UK.

21. Food and Drug Administration (FDA). NDA 205425 tentative approval. Silver Spring: FDA; 2015. Available from: http://www. accessdata.fda.gov/drugsatfda_docs/appletter/2015/2054250 rig1soooTAltr.pdf

22. de Jose MI, Jimenez de Ory S, Espiau M, Fortuny C, Navarrohttp://ML, Soler-Palacín P, et al. A new tool for the paediatric HIV research: general data from the Cohort of the Spanish Paediatric HIV Network (CoRISpe). BMC Infect Dis. 2013;13:2.

23. Bland R, Coovadia H, Coutsoudis A, Rollins N, Newell M. Cohort profile: mamanengane or the Africa centre vertical transmission study.Int J Epidemiol. 2010;39(2):351-60. DOI: 10.1093/ije/dyp165 PMID: 19336438

24. Violari A, Cotton MF, Gibb DM, Babiker AG, Steyn J, Madhi SA, et al. Early antiretroviral therapy and mortality among HIV-infected infants. N Engl J Med. 2008;359(21):2233-44. DOI: 10.1056/NEJMoao800971 PMID: 19020325

25. World Health Organization (WHO). Consolidated guidelines on the use of antiretroviral drugs for treating and preventing HIV infection: recommendations for a public health approach June 2013. Geneva: WHO; 2013. Available from: http://www.who.int/ hiv/pub/guidelines/arv2013/en/

\section{License and copyright}

This is an open-access article distributed under the terms of the Creative Commons Attribution (CC BY 4.0) Licence. You may share and adapt the material, but must give appropriate credit to the source, provide a link to the licence, and indicate if changes were made.

This article is copyright of the authors, 2016. 